\title{
Tolerance and Intolerance for Uncertainty as Predictors of Decision Making and Risk Acceptance in Gaming Strategies of The Iowa Gambling Task
}

\author{
Tatiana V. Kornilova ${ }^{a^{*}}$, Maria A. Chumakova ${ }^{b}$, Sergey A. Kornilov ${ }^{c}$ \\ a Department of Psychology, Lomonosov Moscow State University, Moscow, Russia \\ ${ }^{\mathrm{b}}$ Faculty of Social Sciences / School of Psychology, National Research University Higher School \\ of Economics, Moscow, Russia \\ ${ }^{c}$ Department of Psychology, Saint Petersburg State University, Saint Petersburg, Russia \\ *Corresponding author. E-mail: tvkornilova@mail.ru
}

Background. This article reports on the results of an empirical study of interrelationships between indicators of decision-making strategies (indexed by the Iowa Gambling Task, IGT) and traits of tolerance and intolerance for uncertainty that capture the unity of cognitive and personality components of situational representations.

Objective. Our study tested the hypothesis that overcoming uncertainty in decision making goes beyond cognitive representations of the task but instead is rooted in the construction of the amodal image of an uncertain situation that captures the meaning regulation of perception and action. We hypothesized that when a person is faced with multi-stage decisions, their strategies reflect the contribution of individual differences in attitudes towards uncertainty.

Design. Using data obtained from $\mathrm{n}=60$ typically developing adults $(68 \%$ men; $\mathrm{M}_{\mathrm{age}}=30.58$ ), we examined the contribution of tolerance/intolerance for uncertainty to a variety of IGT dependent variables at five different stages of the game.

Results. The data was analyzed using the mixed linear model method as implemented in the lme4 package for $\mathrm{R}$. The results indicated that tolerance for uncertainty significantly contributes to the initial level of behavioral risk, ensuring readiness for decision making under uncertainty.

Conclusion. Tolerance for uncertainty plays an important role in early stages of orientation in an uncertain modeled game situation, and contributes to the productive development of probabilistic expectations. Intolerance for uncertainty, on the other hand, was shown to contribute to risk in decision making after trial failure, potentially limiting learning in uncertain conditions through risk aversion.

Keywords: decision making, Iowa Gambling Task (IGT), tolerance for uncertainty, tolerance for ambiguity, intolerance for uncertainty, risk acceptance 


\section{Introduction}

Despite significant advances in research on decision making (DM) in the recent decades, the sources of individual differences in cognitive strategies and personal choices under uncertain conditions remain largely understudied, with a particular lack of studies conducted in the individual differences paradigm - i.e., studies that would examine and characterize the inter-individual variation in decision making and associated traits and abilities. One of the reasons for this gap in the literature is historical. Decision-making research was previously studied mainly within the framework of cognitive psychology and organizational decision research, and neglected the individual's prognostic anticipatory activity as a source of meaningful variation. Prognostic activity is manifested in active anticipation and forecasting during decision making, as well as processes of goal setting and thinking that underlie the constructions of "neoformations" - mental products that are used both to achieve the decision-making goal but also to monitor the individual ability vs. task demand fit and resource requirements.

Decision making was fairly recently reconceptualized in psychological studies to encompass dynamic control of uncertainty, replacing traditional dichotomies of rational-irrational, cognitive-emotional and other oppositions in decision-making regulatory processes (Gigerenzer, 2015; Hastie \& Dawes, 2010; Osman, 2010). This is in part driven by the acquisition of studies of decision-making regulation of a new social meaning, reflecting the notion of modern man as living in highly complex, uncertain conditions in the vast majority of life domains. This shift brings with it a new understanding of the insufficiency of generally reductionist claims that postulate a general link between personality and decision making, and highlights the need for systematic, rigorous studies of decision making in the individual differences framework that would adequately consider decision making as being realized by a person with certain attributes - abilities, traits, and acquired behavioral and decision-making strategies - that govern the actual process of decision making as it unfolds under conditions of uncertainty.

Such traits can be classified into stable (dispositional) personality traits that are fairly independent from situational choice preferences, and dynamic traits that capture attitudes towards uncertainty as an overarching construct. Whereas a person's global "character" reflects a combination of established traits and patterns of behavior, attitudes towards uncertainty capture the complementary spectrum of decision-making regulation in situations when established strategies no longer apply - for example, under new, unusual, atypical, internally contradictory, or ambiguous conditions. Tolerance and intolerance for uncertainty are two such traits, and previous research (including by the authors of this article) unequivocally points to the their important role in a wide array of decision-making situations characterized by uncertainty.

Cognitive versus emotional regulation of decision making in the Iowa Gambling Task. In psychology, the conceptualization of personal regulation of decision making is tied to the early studies of emotional regulation of choice. Studies of prediction processes have tended to lean towards the primacy of the emotional domain since Damasio put forward the "somatic markers" hypothesis (Damasio, Everitt, \& Bishop, 1996). The somatic markers themselves are viewed as a special 
type of reaction, with an associated host of experienced signals that are formed on the basis of previous individual experience, and are subjectively experienced as suspicions, anticipations, and "gut feelings". Popularization of this concept was promoted by the fact that it serves as a theoretical support for the neurophysiological basis of feedback and for the specificity of prognostic activity in different clinical groups. Notably, these patterns are revealed on the basis of a single experimental model of the Iowa Gambling Task (IGT; Bechara, Damasio, Damasio, \& Tranel, 2005) - a model situation that presents the participant with a problem where they are asked (without any prior knowledge) to win as much game money as possible by drawing cards from "bad" and "good" decks that contain cards with a particular gain-loss probabilistic and monetary structure. To date, only a small portion of IGT studies have been conducted with typically developing participants. Some recent research suggests that in typical samples, decision making in the IGT is linked with cognitive traits such as emotional and analytical intelligence (Webb, DelDonno, \& Killgore, 2014).

The goal of this article is not only to present empirical data broadening our understanding of decision making, but also to provide a tentative theoretical account of the sources of intellectual activity of a person, which could be manifest in different types of prognostic tasks. In Russian psychology, the concept of the "world image" , proposed by Leontiev (1975) and further developed by his colleagues, is well established. It focuses on a different aspect of anticipation the feedback from primary representations of a situation under uncertainty, namely, the prognostic activity directed by the amodal deep structures afforded by the amodal "world image". These structures include, in particular, individual representations of meanings and the processes of hypothesis development and testing. Since the development of anticipatory activity encompasses its objective content as well as the guiding role of the "world image", studying the dynamic regulation of decisions under uncertain and risky conditions (Smirnov, Chumakova, \& Kornilova, 2016) poses a diagnostic problem (in terms of which processes reach the leading level of regulation), and related theoretical accounts necessitate the transition to higher-level concepts, indexing prognostic activity that is not reducible to the visceral somatic feedback loop.

Tolerance for uncertainty as a key index of attitude towards uncertainty. Tolerance and intolerance for uncertainty are key variables in the overarching system of personal regulation of choice and decision making under conditions of uncertainty. Although the concept of tolerance for uncertainty introduced by Frenkel-Brunswick $(1948,1949)$ is subject to substantial definitional heterogeneity, it should be noted that the term itself was originally introduced as characteristic of both cognitive and personality domains. Importantly, over time tolerance and intolerance for uncertainty shifted from being viewed as two poles of the same concept continuum to being viewed as partially independent constructs and dimensions of personality (Kornilova, 2010). Furthermore, intolerance for uncertainty has been differentiated

1 "World image" — system of multilevel and coherent hypotheses continuously generated by the subject to meet the stimuli of the surrounding world 
from intolerance for ambiguity (Buhr \& Dugas, 2006), and within the concept of intolerance for uncertainty, intolerance for uncertainty and intolerance for subjective uncertainty also diverged on conceptual as well as empirical grounds (Grenier, Barrette, \& Ladoucer, 2005). Intolerance for uncertainty is primarily tapping into uncertainty as a stressful factor that disrupts one's ability to act, with the uncertain situations generally portrayed and perceived as fundamentally negative (something to be avoided), and uncertainty itself being perceived as assuming certain degrees of "unfairness" or "wrongfulness".

Some recent approaches suggest that terminological differences can be circumvented by ascribing specific terms to subfields that study the relevant construct e.g., tolerance for ambiguity would fall under the category of general psychology concepts, whereas tolerance for uncertainty would fall under the category of clinical psychology concepts (Rosen, Ivanova, \& Knäuper, 2014). Such artificial separations are in conflict with the observations that both general and cognitive psychology utilize the term "tolerance for uncertainty" with a frequency that is similar to that in clinical psychology (Tobin, Loxton, \& Neighbors, 2014). Additional considerations were put forward proposing that tolerance for ambiguity is more proximal to the dimension of stimulus properties, whereas tolerance for uncertainty is more proximal to the dimension of emotional responses of the person who experiences uncertainty towards it. Notably, the two concepts also appear to differ along the temporal dimension, with tolerance for ambiguity reflecting responses to uncertainty here and now, whereas tolerance for uncertainty reflects the orientation towards an undetermined future (Furnham \& Marks, 2013). Furnham and Marks (2013) came to the conclusion that tolerance for uncertainty should be regarded as a factor of the second or third order in relation to the primary Big Five personality traits (Extraversion, Openness, Agreeableness, Conscientiousness, and Neuroticism), as it refers to the entire spectrum of the Big Five.

So far, we have provided the reader with an overview of the concepts that link overcoming uncertainty and task-based prognostic activity in decision making. This activity is realized through the development and implementation of individual decision-making strategies. We believe that the Iowa Gambling Task is an underutilized measure of individual differences in decision making, with an untapped potential for revealing the nature and the sources of individual differences in decision making, through the examination of prognostic strategies involved in the cognitive orientation in an uncertain situation. These strategies have the potential to resolve the traditional conflict between viewing emotional vs. intellectual components of decision-making regulation as being primary (Bechara, Damasio, Damasio, \& Anderson, 1994). As mentioned above, individual correlates of IGT performance are understudied in non-clinical samples (Buelow \& Suhr, 2009), and the present article aims to bridge this gap in the literature by explicitly addressing it in an empirical study of IGT performance correlates, while focusing on tolerance-intolerance for uncertainty as overarching traits contributing to decision making.

The role of tolerance for uncertainty in regulation of decision making: a hypothesis. In the empirical study reported below, we aimed to identify the rela- 
tionships between decision-making strategies in the IGT and individual differences in traits of tolerance/intolerance for uncertainty. Acceptance of challenges of uncertainty requires not only readiness for change, uncertainty, and associated complexity and novelty, but also readiness for a particular cognitive attitude towards a situation characterized by multiple dynamic changes, since these attitudes allow for a flexible orientation towards pragmatic and information-seeking strategies (e.g., hypothesis-testing or research-like behavior throughout the game).

The IGT is frequently analyzed through the lens of the behavioral index of the preference for "safe" or "advantageous" decks of cards. Webb and colleagues (2014) previously suggested that deck preference rises sharply in the first 20 (out of 100) IGT trials, and reaches a plateau around the $40^{\text {th }}$ trial. As an alternative, we examined the contribution of tolerance and intolerance for uncertainty to participants' performance in the IGT by explicitly modeling the dynamic nature of this task through a longitudinal data analysis approach both to establishing the time course of decision making in the IGT and to quantifying the contribution of these traits to IGT performance parameters (e.g., the intercepts and slopes for overall gain of game money, preference for bad vs. good decks, and number of deck switches after a monetary in-game loss). We specifically hypothesized that at the initial stages of the IGT the choices will be significantly associated with a positive attitude toward uncertainty.

\section{Method}

\section{Participants}

A total of 60 individuals in the age range from 18 to 52 years $(M=30.58, S D=10.61$; $68 \%$ males, $32 \%$ females) participated in this study. Participants were Moscow State University undergraduate students (approximately $1 / 3$ of the sample) or typically developing adults recruited for the study externally.

\section{The Iowa Gambling Task}

We utilized the adapted Russian version of the computerized (HTML) IGT developed by Grasmann and Wagnermakers (2005). In the computerized procedure of this task, the participants make 100 consecutive choices of one card from any of the four decks on the screen. The goal is to win as much game money as possible. For each choice, the card represents a particular reward structure operationalized in the gain and loss amounts, with a particular probability of long-term losses and gains being a property of each deck. Two decks contain high-risk cards: They give relatively high wins ( $\$ 100$ ), but also rare yet significant losses (up to $\$ 1,250$ ), and therefore a long-term preference of these decks leads to an overall loss. Two other decks allow for a gradual accumulation of small gains (\$50) with small penalties, and in the long run lead to a larger net gain of game money.

Procedurally, the task can be regarded as learning to solve a prognostic task under conditions of uncertainty, where participants face the need to create and process probabilistic hypotheses about possible gains or losses engrained in the 
structure of the decision-making environment (decks and cards). Since decision making in the IGT unfolds over time (in a sequence of 100 trials), decisional strategies reflected in behavioral performance in the IGT have temporal characteristics, and can be appropriately modeled by hierarchical linear modeling (or mixed linear modeling), capturing the dynamics of choices depending on the reduction in uncertainty levels of the situation.

We analyzed the IGT data by splitting it into five blocks (20 trials each), consistent with previous research (Brevers, Bechara, Cleermans, \& Noël, 2013). While the first block performance effectively indexes cognitive orientation under uncertainty, the fifth block performance can be viewed as indexing full-fledged decisionmaking processes under conditions where the probabilities of gains and losses have been already established.

\section{New Questionnaire of Tolerance/Intolerance for Uncertainty}

We used the New Questionnaire of Tolerance/Intolerance for Uncertainty (Kornilova, 2010) to measure attitudes towards uncertainty. This was a self-report questionnaire constructed based on the re-analysis of Furnham's (1994) tolerance for uncertainty questionnaire, which itself included several measures. We previously showed that the questionnaire has a three-factor structure in typically developing Russian samples, and can be used to obtain reliable indices of tolerance for uncertainty (TU), intolerance for uncertainty (ITU), and interpersonal intolerance for uncertainty (IITU).

\section{Results}

The data were analyzed using the mixed linear model method (Baayen, 2008) as implemented in the lme4 package for R. Block number (1 to 5), squared term for the block number (allowing for nonlinearity of learning), demographic variables (age and sex), and tolerance/intolerance for uncertainty variables were entered into the model as fixed effects. The model also included random effects of participants on the initial starting point (intercept) and slope.

In the conditional growth model, demographic variables and tolerance/intolerance for uncertainty were allowed to influence both intercept and slope. The model parameters are summarized in Table 1. Of note is that demographic variables did not significantly predict either of the three dependent variables or their slope parameters.

The analyses revealed a complex pattern of results. First, we found that participants tended to earn more money as they progressed through the experiment, with a pattern of change consistent with that previously reported for the task (slowing down growth). Moreover, initial gains in the IGT were predicted positively by tolerance for uncertainty $(B=5.68, S E=2.93, t=1.94)$.

Second, we found that the preference for disadvantageous IGT decks decreased linearly over the course of the experiment $(B=-.04, S E=.02, t=-2.03)$. At the same time, the initial preference for "bad" decks was positively predicted by tolerance for uncertainty $(B=0.006, S E=0.003, t=2.13)$. 
Table 1

Summary of Fixed Effects for the Mixed Models with IGT Performance as Dependent Variables

\begin{tabular}{cccccccccc}
\hline & \multicolumn{3}{c}{ Net Gain } & \multicolumn{4}{c}{ Bad Decks } & \multicolumn{3}{c}{ Loss Switches } \\
\cline { 2 - 9 } Parameter & B & SE & $\mathbf{t}$ & B & SE & t & B & SE & t \\
\hline Intercept & $1,514.06$ & 52.70 & $28.73^{*}$ & .53 & .05 & 10.39 & 3.85 & .50 & 7.72 \\
Block & $1,557.07$ & 78.10 & $19.94^{*}$ & -.04 & .02 & $-2.03^{*}$ & -.32 & .55 & -.58 \\
Sex & 104.97 & 70.63 & 1.49 & .07 & .07 & 1.09 & .85 & .67 & 1.27 \\
Age & -3.46 & 2.86 & -1.21 & -.002 & .003 & -.90 & -.03 & .03 & -1.22 \\
TU & 5.68 & 2.93 & $1.94^{\mathrm{t}}$ & .006 & .003 & $2.13^{*}$ & -.04 & .03 & -1.51 \\
ITU & 1.25 & 2.23 & .56 & .002 & .002 & .90 & -.05 & .02 & $-2.32^{\star}$ \\
Block & -26.13 & 12.45 & $-2.10^{*}$ & $\mathrm{n} / \mathrm{a}$ & $\mathrm{n} / \mathrm{a}$ & $\mathrm{n} / \mathrm{a}$ & .05 & .13 & .38 \\
Block:Sex & -8.01 & 104.68 & -.08 & .02 & .03 & .93 & -.40 & .73 & -.55 \\
Block:Age & .42 & 4.24 & .10 & -.001 & .001 & -.60 & .02 & .03 & .52 \\
Block:TU & 6.18 & 4.34 & 1.42 & -.002 & .001 & -1.42 & .03 & .03 & 1.12 \\
Block:ITU & 3.59 & 3.30 & 1.09 & -.001 & .001 & -.71 & .05 & .02 & $2.14^{*}$ \\
Block:Sex & 23.09 & 16.69 & 1.38 & $\mathrm{n} / \mathrm{a}$ & $\mathrm{n} / \mathrm{a}$ & $\mathrm{n} / \mathrm{a}$ & -.02 & .17 & -.10 \\
Block:Age & -.63 & .68 & -.94 & $\mathrm{n} / \mathrm{a}$ & $\mathrm{n} / \mathrm{a}$ & $\mathrm{n} / \mathrm{a}$ & -.0002 & .007 & -.02 \\
Block:TU & -.93 & .69 & -1.34 & $\mathrm{n} / \mathrm{a}$ & $\mathrm{n} / \mathrm{a}$ & $\mathrm{n} / \mathrm{a}$ & -.008 & .007 & -1.17 \\
Block:ITU & -.56 & .52 & -1.07 & $\mathrm{n} / \mathrm{a}$ & $\mathrm{n} / \mathrm{a}$ & $\mathrm{n} / \mathrm{a}$ & -.01 & .005 & $-1.86^{\mathrm{t}}$ \\
\hline
\end{tabular}

Notes: ${ }^{*} p<0.05 ;{ }^{t} p<0.10 . T U-$ tolerance for uncertainty. ITU - intolerance for uncertainty. $B-$ mixed model regression coefficient with its standard error (SE).

Third, we found that switching to other decks after facing a loss was relatively constant throughout the course of the experiment for the "average" participant. However, intolerance for uncertainty predicted the intercept negatively $(B=-0.05$, $S E=0.02, t=-2.32$ ). For participants with higher intolerance for uncertainty, fewer deck changes were observed after a loss at this stage of the IGT. At the same time, intolerance for uncertainty positively predicted the slope parameter for this index $(B=0.05, S E=0.02, t=2.14)$, thereby suggesting that for individuals with high intolerance for uncertainty, the proportion of deck switches increases over time to a larger extent than for individuals with low tolerance for uncertainty.

\section{Discussion}

We examined tolerance/intolerance for uncertainty as potential sources of individual differences in the dynamic parameters of decision making in the Iowa Gambling Task. We found that tolerance and intolerance for uncertainty acted as significant predictors of IGT performance, although they predicted different indices. 
These findings suggest that tolerance/intolerance for uncertainty modulate decision-making strategies under conditions of uncertainty. Tolerance for uncertainty, for example, predicted the baseline level of monetary IGT performance; although participants who had higher tolerance for uncertainty were more likely to choose disadvantageous decks in the IGT at the beginning of the experiment, they also showed higher overall profit, compared to participants with lower tolerance for uncertainty. This finding suggests that tolerance for uncertainty plays a pivotal role in determining the initial level of risk readiness under conditions of uncertainty, consistent with prior findings that linked tolerance for uncertainty and risk readiness using behavioral measures of risk readiness (Kornilova, 2016) and choice processes in the IGT with sensation seeking (Suhr \& Tsandis, 2007).

Tolerance for uncertainty played an important role in orientation to the dynamic changes in the decision-making environment and the productive development of probabilistic anticipations. At the same time, the results of the study suggest that higher intolerance to uncertainty was associated with a decrease in "research activity" (risk aversion) after exposure to an in-game loss of money. This finding is concordant with the accounts of intolerance for uncertainty as an index of risk aversion and rejection of uncertainty as well as with the empirical evidence that this personality trait is related to avoidance coping strategies when decisions are made under conditions of uncertainty (Kornilova, 2013).

The modeling approach to the analysis of IGT parameters allowed us to go beyond simple correlation analysis and revealed a complex picture of the regulatory processes behind the measured indicators of gaming (and decision-making) strategies. Overall, decision making under uncertain conditions is partially modulated, therefore regulated by tolerance and intolerance for uncertainty. Interestingly, tolerance for uncertainty appears to regulate basic risk readiness that underlies cognitive learning in the initial stages of decision making, while intolerance for uncertainty regulates risk propensity after failure/loss, potentially limiting learning under conditions of uncertainty, through risk aversion and increased sensitivity to negative outcomes. These findings are noteworthy because they shape an alternative methodological approach to studying the functional relationships between cognitive and personality traits and processes that are involved in decision making and choice regulation.

The study has several limitations. First and foremost, the findings should be replicated in samples of larger size and characterized by prominent variation in the studied traits and processes. Second, it is possible that our analytical approach did not adequately capture qualitative decision-making strategies that characterize different participants. Third, this analysis did not include a measure of intelligence, a possible baseline performance predictor of the IGT (Smirnov, Chumakova, Kornilov, Krasnov, \& Kornilova, 2017).

Our study provides general support for the notion of the amodal world image that focuses on a different aspect of individual regulation of anticipatory decisionmaking strategies than the hypothesis of "somatic markers": i.e., on higher levels of a person's prognostic activity regulation by overarching traits of attitudes towards uncertainty. This does not negate the importance of somatic markers that signal success or failure, but instead highlights the irreducibility of decision making to 
somatic markers that are placed at the "vertex" levels of anticipatory activity regulation and that are instead modulated by personality traits. These "vertex" levels are: (a) positive acceptance of uncertain conditions (as a challenge to one's abilities) and (b) uncertainty aversion combined with reliance on known facts (already defined components of a situation) in one's search for clarity.

\section{Acknowledgments}

The authors thank Y.V. Krasavtseva for her help with the translation of the early draft of this article. The research was supported by the Russian Foundation for Basic Science (Grant 15-06-10404).

\section{References}

Baayen, R.H. (2008). Analyzing linguistic data: A practical introduction to statistics using R. Cambridge, UK: Cambridge University Press. https://doi.org/10.1017/CBO9780511801686

Bechara, A., Damasio, A.R., Damasio, H., \& Anderson, S.W. (1994). Insensitivity to future consequences following damage to human prefrontal cortex. Cognition, 50(1), 7-15. https://doi. org/10.1016/0010-0277(94)90018-3

Bechara, A., Damasio, H., Tranel, D., \& Damasio, A.R. (2005). The Iowa Gambling Task and the somatic marker hypothesis: some questions and answers. Trends in Cognitive Sciences, 9(4), 159-162. https://doi.org/10.1016/j.tics.2005.02.002

Brevers, D., Bechara, A., Cleeremans, A., \& Noël, X. (2013). Iowa Gambling Task (IGT): twenty years after - gambling disorder and IGT. Frontiers in Psychology, 4. https://doi.org/10.3389/ fpsyg.2013.00665

Buelow, M.T., \& Suhr, J.A. (2009). Construct validity of the Iowa Gambling Task. Neuropsychology Review, 19(1), 102-114. https://doi.org/10.1007/s11065-009-9083-4

Buhr, K., \& Dugas, M. J. (2006). Investigating the construct validity of intolerance for uncertainty and its unique relationship with worry. Journal of Anxiety Disorders, 20(2), 222-236. https://doi.org/10.1016/j.janxdis.2004.12.004

Damasio, A.R., Everitt, B.J., \& Bishop, D. (1996). The somatic marker hypothesis and the possible functions of the prefrontal cortex. Philosophical Transactions: Biological Sciences, 1413-1420. https://doi.org/10.1098/rstb.1996.0125

Frenkel-Brunswik, E. (1949). Intolerance for ambiguity as an emotional and perceptual personality variable. Journal of Personality, 18(1), 108-143. https://doi.org/10.1111/j.1467-6494.1949. tb01236.x

Furnham, A., \& Marks, J. (2013). Tolerance for ambiguity: A review of the recent literature. Psychology, 4(09), 717. https://doi.org/10.4236/psych.2013.49102

Gigerenzer, G. (2015). Simply rational: Decision making in the real world.. https://doi.org/10.1093/ acprof:oso/9780199390076.001.0001

Grasman, R.P., \& Wagenmakers, E.J. (2005). A DHTML implementation of the Iowa Gambling Task. Retrieved on January 1, 2018 from http://purl.oclc.org/NET/rgrasman/jscript/Iowa GamblingTask

Grenier, S., Barrette, A. M., \& Ladouceur, R. (2005). Intolerance for uncertainty and intolerance for ambiguity: Similarities and differences. Personality and Individual Differences, 39(3), 593-600. https://doi.org/10.1016/j.paid.2005.02.014

Hastie, R., \& Dawes, R. M. (2010). Rational choice in an uncertain world: The psychology of judgment and decision making. NY: Sage. 
Kornilova, T.V. (2010). Novyi oprosnik tolerantnosti-intolerantnosti k neopredelennosti [New questionnaire of tolerance-intolerance for uncertainty]. Psikhologicheskii zhurnal, 31(1), $74-86$

Kornilova, T.V. (2013). Mel'burnskii oprosnik prinyatiya reshenii: russkoyazychnaya adaptatsiya [Melbourne decision making questionnaire: a Russian adaptation]. Psikhologicheskie issledovaniya, 6(3), 4. Retrieved on July 20, 2018 from http://psystudy.ru/index.php/ num/2013v6n31/883-kornilova31.html

Kornilova, T.V. (2016). Intellektual'no-lichnostnyi potentsial cheloveka v usloviyakh neopredelennosti i riska [Intellectual-personality potential of a person in conditions of uncertainty and risk]. St. Petersburg: Nestor- Istoriya

Leontiev, A.N. (1975). Deyatel'nost'. Soznanie. Lichnost'. [Activity. Consciousness. Personality]. Moscow: Politizdat.

Osman, M. (2010). Controlling uncertainty: A review of human behavior in complex dynamic environments. Psychological Bulletin, 136(1), 65. https://doi.org/10.1037/a0017815

Rosen, N.O., Ivanova, E., \& Knäuper, B. (2014). Differentiating intolerance for uncertainty from three related but distinct constructs. Anxiety, Stress \& Coping, 27(1), 55-73. https://doi.org /10.1080/10615806.2013.815743

Smirnov, S.D., Chumakova, M.A., \& Kornilova, T.V. (2016). Obraz mira v dinamicheskom kontrole neopredelennosti [The image of the world in dynamic control of uncertainty], Voprosy Psihologii, 4, 3-13.

Smirnov, S.D., Chumakova, M.A., Kornilov, S.A., Krasnov, E.V., \& Kornilova, T.V. (2017). Kognitivnaya i lichnostnaya regulyatsiya strategii resheniya prognosticheskoi zadachi (na materiale Iowa Gambling Task) [Cognitive and personality regulation of strategies for solving a prognostic task (based on the Iowa Gambling Task)], Moscow University Psychology Bulletin. Series 14. Psychology, 3, 39-59. https://doi.org/10.11621/vsp.2017.03.39

Suhr, J.A., \& Tsanadis, J. (2007). Affect and personality correlates of the Iowa Gambling Task. Personality and Individual Differences, 43(1), 27-36. https://doi.org/10.1016/j.paid.2006.11.004

Tobin, S.J., Loxton, N.J., \& Neighbors, C. (2014). Coping with causal uncertainty through alcohol use. Addictive behaviors, 39(3), 580-585. https://doi.org/10.1016/j.addbeh.2013.11.009

Webb, C.A., DelDonno, S., \& Killgore, W.D. (2014). The role of cognitive versus emotional intelligence in Iowa Gambling Task performance: What's emotion got to do with it? Intelligence, 44, 112-119. https://doi.org/10.1016/j.intell.2014.03.008

Original manuscript received October 28, 2017

Revised manuscript accepted July 12, 2018

First published online September 30, 2018 